\title{
A compreensão de profissionais da atenção primária à saúde sobre as práticas da terapia ocupacional no NASF
}

\author{
Andréa Saraiva de Andrade ${ }^{a}$, Ilka Veras Falcáob \\ ${ }^{a}$ Hospital Municipal Pedro I, Prefeitura Municipal de Campina Grande, Campina Grande, PB, Brasil. \\ ${ }^{b}$ Departamento de Terapia Ocupacional, Universidade Federal de Pernambuco - UFPE, Recife, PE, Brasil.
}

\begin{abstract}
Resumo: Introdução: A ampliação da equipe multiprofissional na Atenção Primária à Saúde (APS) inseriu categorias profissionais que tradicionalmente atuavam no atendimento de média e alta complexidade. O desconhecimento das atribuições dessas profissões pode ser um entrave à efetivação da interdisciplinaridade e do compartilhamento de práticas. Objetivo: O objetivo deste estudo foi analisar a compreensão dos profissionais da equipe de Saúde da Família e do Núcleo de Apoio à Saúde da Família (NASF) quanto às práticas da terapia ocupacional na APS, como membro da equipe NASF. Método: Esta pesquisa caracteriza-se como exploratória, de campo qualitativo, com dados colhidos individualmente, por meio de entrevista semiestruturada, aplicada com profissionais de uma equipe de Saúde da Família e uma equipe NASF. Utilizou-se a análise de conteúdo para tratamento dos dados. Resultados: identificou-se que a compreensão das equipes sobre a atuação do terapeuta ocupacional é parcial, associando sua atuação basicamente à saúde mental e à reabilitação, confundindo suas práticas com as atribuições de outros profissionais da equipe. Conclusão: Houve dificuldade para diferenciar práticas próprias do terapeuta ocupacional, mesmo quando há compartilhamento de trabalho. Isso sugere a necessidade de implementar estratégias, como o matriciamento, para superação das lacunas no conhecimento quanto às especificidades de cada profissão que atua na APS.
\end{abstract}

Palavras-chave: Atenção Primária à Saúde, Terapia Ocupacional, Prática Profissional, Profissional da Saúde, Estratégia Saúde da Família.

\section{Primary health care professionals understanding on the practices of Occupational Therapy in the family health support center}

\begin{abstract}
Introduction: The expansion of the multi-professional team in Primary Health Care (APS) input professional categories that have traditionally worked in the service of medium and high complexity. The lack of knowledge on the assignments of these new jobs can be an obstacle to effective interdisciplinary and sharing practices. Objective: The study aimed to analyze the professional healthcare team understanding on the Family and Support Center for Family Health (NASF) and the practices of Occupational Therapy in APS, as a member of NASF team. Method: This study is characterized as exploratory and qualitative field, with data collected individually, through semi-structured interviews with professionals of a Family Health Team and a NASF team. We used content analysis for data processing. Results: We identified that the understanding of the teams on the role of the occupational therapist is partial, linking their practices basically with mental health and rehabilitation, confusing their duties with the other team members. Conclusion: It was difficult to differentiate occupational therapist own practices, even when the work is shared. This suggests the need to implement strategies, such as matrix-based strategies to overcome the gaps in knowledge between the team and the specifics of each profession engaged in APS.
\end{abstract}

Keywords: Primary Health Care, Occupational Therapy, Professional Practice, Health Personnel, Family Health Strategy.

Autor para correspondência: Andréa Saraiva de Andrade, Hospital Municipal Pedro I, Rua Dom Pedro I, 605, São José, CEP 58400-404, Campina Grande, PB, Brasil, e-mail: andreasara_to@yahoo.com.br

Recebido em Jan. 26, 2016; $1^{\text {a }}$ Revisão em Abr. 17, 2016; 2 ${ }^{\text {a }}$ Revisão em Maio 31, 2016; Aceito em Ago 9, 2016. 


\section{Introdução}

Desde a criação do Sistema Único de Saúde (SUS), em 1990, ocorreram avanços no que diz respeito à Atenção Primária à Saúde (APS) no Brasil (SILVA; CASOTTI; CHAVES, 2013; BRASIL, 2006). Entre eles, podemos citar a criação do Programa Saúde da Família, que trouxe a possibilidade de uma "mudança de paradigma" nas práticas assistenciais, apresentando, como ponto relevante, a implementação do âmbito preventivo (BRASIL, 1994).

A APS tem por objetivo oferecer ações e serviços de promoção e proteção da saúde, prevenção de agravos, diagnóstico, tratamento, reabilitaçáo e a manutenção da saúde, sendo norteada pela universalidade, acessibilidade, vínculo, continuidade do cuidado, integralidade da atenção, responsabilizaçáo, humanizaçáo, equidade e participaçáo social (BRASIL, 2014; MENDES, 2011).

Seguindo a trajetória de avanços na APS, o êxito do Programa Saúde da Família o consolidou como Estratégia Saúde da Família (ESF), prioritária para a reorganização da APS, capaz de viabilizar a reorientação do processo de trabalho e atingir, de forma mais abrangente, os princípios, as diretrizes e os fundamentos da atenção primária. Além disso, a ESF apresentou potencial para aumentar a resolutividade e o impacto na condiçấo de saúde das pessoas, com uma relevante relação custo-benefício (BRASIL, 2012b).

Para alcançar seus objetivos, a ESF apresenta uma equipe composta de, no mínimo, um médico generalista ou especialista em Saúde da Família ou médico de Família e Comunidade; enfermeiro generalista ou especialista em Saúde da Família; auxiliar ou técnico de enfermagem; e entre quatro e doze Agentes Comunitários de Saúde. Podem ser acrescentados, como parte da equipe multiprofissional, os profissionais de saúde bucal — cirurgião-dentista (generalista ou especialista em Saúde da Família), auxiliar e/ou técnico em saúde bucal (BRASIL, 2012b). A partir de 2008, para ampliar a cobertura e atender às necessidades de saúde da população, a ESF passou a receber suporte do Núcleo de Apoio à Saúde da Família (NASF) (SILVA et al., 2012; BRASIL, 2008).

O NASF tem como diretrizes de trabalho a noção de território, a integralidade, a participação social, a educação popular, a promoção da saúde e a humanização do cuidado, tendo como premissas o apoio às açốes das Equipes de Saúde da Família (EqSF) e a ampliação da resolutividade da APS, com expectativas quanto à corresponsabilidade pela saúde da população, discussão de casos, interdisciplinaridade e articulação da rede de saúde (SILVA et al., 2012). Para alcançar tais objetivos, a parceria entre o NASF e as Equipes de Saúde da Família deve se dar em responsabilidade compartilhada, por meio das demandas identificadas no território, de forma a fortalecer os atributos e a função de ambos na coordenaçáo do cuidado na APS (BRASIL, 2014).

Considerado uma estratégia inovadora, o NASF deve ampliar o alcance assistencial, por incluir diferentes saberes profissionais. A sua composição depende da opção do gestor municipal, devendo ser orientada pelo perfil epidemiológico, pelas necessidades locais e pelas necessidades das equipes de saúde que serão apoiadas pelo NASF (BRASIL, 2014, 2012a).

Nesse contexto, o NASF faz uso de algumas ferramentas - entre elas, o apoio matricial, que organiza o processo de trabalho das equipes e integra as dimensóes de suporte assistencial e técnico-pedagógico. Essas dimensôes abrangem açôes de cuidado aos usuários, além do apoio educativo e da articulaçáo da rede na resoluçáo de problemas para os profissionais (BRASIL, 2014, 2010).

Segundo Campos e Domitti (2007), o apoiador matricial é um profissional com perfil distinto do perfil dos profissionais da EqSF. Com base no seu núcleo de conhecimento, ele agrega recursos e contribui com intervençôes que ampliam a capacidade da equipe e possibilitam a continuidade do cuidado. Para a coordenação da prática compartilhada entre os profissionais dessas equipes, o conhecimento do papel de cada um e a pactuaçáo entre eles tornam-se fundamentais para o processo de trabalho e cuidado à saúde na APS (ELLERY; PONTES; LOIOLA, 2013).

Nessa perspectiva, este trabalho tem por objetivo analisar a compreensão dos profissionais da Equipe de Saúde da Família e do NASF quanto às práticas do terapeuta ocupacional no núcleo.

Considerada uma profissão do campo da saúde, da educação e social, a Terapia Ocupacional é uma das profissóes que pode integrar a equipe NASF, inserida Portaria $n^{\circ} 154 / 2008$, documento oficial de criação do NASF. O terapeuta ocupacional é um profissional que reúne tecnologias para emancipação e autonomia das pessoas que, por comprometimentos físicos, sensoriais, mentais, psicológicos e/ou sociais, apresentem dificuldades no desempenho dos seus papéis, na inserção ou participação social (AMERICAN..., 2015; BRASIL, 2008; JACOBS, 2006).

A especificidade da Terapia Ocupacional é a compreensão do desempenho e dos papéis ocupacionais, das interaçóes entre o ser humano, o seu fazer e o contexto em que vive, como fundamental 
para influenciar o estado de saúde e doença. $\mathrm{O}$ autocuidado, o lazer e as atividades produtivas são compreendidos como áreas de desempenho ocupacional e como estratégias para alcançar a independência funcional, o desenvolvimento pessoal, a prevenção de incapacidades e a manutenção da saúde e das condiçôes de participação social (AMERICAN..., 2015).

Dessa forma, a APS é um espaço de atuação para o terapeuta ocupacional, especialmente pela capacidade desse profissional de analisar o cotidiano e de promover atividades significativas, levando em consideraçáo o contexto de vida e os planos de cuidado pessoais ou comunitários (BAISSI; MAXTA, 2013; LOMBARDO; AYUSO, 2012). É possível observar a atuação de terapeutas ocupacionais no âmbito da APS, em açóes de prevenção e promoção da saúde, como também no apoio matricial às equipes (PAIVA et al., 2013).

No entanto, Bassi, Malfitano e Bianchi (2012) ressaltam o direcionamento das intervençôes dos terapeutas para as pessoas com deficiência, ao mesmo tempo que verificam o crescimento significativo na discussão do tema APS com outras clientelas, nas publicaçóes mais recentes.

\section{Método}

Trata-se de um estudo exploratório de campo, com metodologia qualitativa. A pesquisa foi realizada na cidade do Recife (PE), tendo como amostra uma equipe NASF que é campo de formação e orientação das autoras, a partir do Programa de Residência Multiprofissional em Saúde da Família da Universidade Federal de Pernambuco (UFPE); e uma equipe escolhida aleatoriamente, dentre as quatro que atuam na Unidade de Saúde da Família (USF) coberta por esta equipe NASF.

Foram incluídos todos os profissionais do NASF e da Equipe de Saúde da Família sorteada e excluídos os profissionais que tinham tempo de trabalho inferior a seis meses ou que estavam afastados por licença, férias ou qualquer outro motivo. $\mathrm{O}$ Termo de Consentimento Livre e Esclarecido (TCLE) foi lido e assinado pelos profissionais, para que pudessem participar do estudo, em respeito à Resolução no 466/2012 (BRASIL, 2012a).

A coleta de dados foi realizada no período de julho a setembro de 2014 e se deu mediante entrevista semiestruturada, que contemplou questôes relativas à caracterização dos entrevistados (tempo de vínculo, profissão, equipe e experiência profissional) e à compreensão quanto às práticas do terapeuta ocupacional no NASF. As entrevistas foram gravadas em áudio, transcritas na íntegra e, em seguida, analisadas mediante a aplicação da análise de conteúdo de Bardin (1977), pela técnica de análise temática, seguindo a estrutura de fases: pré-análise, exploração, tratamento, inferência e interpretação. Os dados foram categorizados a partir dos blocos temáticos: a) Práticas desenvolvidas pelo terapeuta ocupacional na visão da equipe de saúde; b) A compreensão das equipes de saúde sobre o potencial de atuação do terapeuta ocupacional e sua importância no NASF; e c) Os desafios para as práticas da Terapia Ocupacional no NASF.

\section{Resultados e Discussão}

Inicialmente serão apresentadas as informaçôes que retratam o perfil dos profissionais participantes desta pesquisa. A equipe NASF era composta de cinco profissionais (duas assistentes sociais, uma fisioterapeuta, uma fonoaudióloga e uma psicóloga) e da Equipe de Saúde da Família, formada por doze profissionais, entre as quais: três de nível superior (uma médica, uma enfermeira, uma cirurgiā-dentista), nove de nível técnico ou médio (uma técnica em enfermagem, uma técnica em saúde bucal, uma auxiliar em saúde bucal e seis Agentes Comunitárias de Saúde). Não houve recusa por parte das profissionais para participação.

Todas as profissionais eram do sexo feminino, com média de idade de 38,6 anos. Quanto ao tempo de vínculo, foi observado que as profissionais com nível médio e técnico de escolaridade estão há mais tempo vinculadas à equipe - o período de vinculação compreende entre cinco e dezessete anos. As profissionais com nível superior de escolaridade apresentam período mínimo de três anos e máximo de seis anos e seis meses.

Em relação à experiência na APS - com exceção da auxiliar em saúde bucal, que trabalhou por um ano em outra USF -, para as profissionais com nível médio e técnico de escolaridade, o trabalho na USF foi a primeira experiência neste nível de atenção à saúde. Desde então, elas realizam capacitaçóes promovidas pela Secretaria de Saúde do município. No que se relaciona às profissionais com nível superior de escolaridade, três náo tiveram outra experiência na APS antes do vínculo com a USF; as demais profissionais apresentaram experiência em outras unidades de saúde, por período mínimo de dois e máximo de dez anos. Serão discutidas, a seguir, as opiniôes das profissionais acerca das práticas já desenvolvidas pelo terapeuta ocupacional, das ações que poderiam desenvolver, 
do potencial de sua atuaçáo, bem como dos desafios para as práticas da Terapia Ocupacional no NASF.

\subsection{Práticas desenvolvidas pelo terapeuta ocupacional na visão da equipe de saúde}

No que diz respeito ao conhecimento das práticas do terapeuta ocupacional por parte das profissionais com nível médio e técnico de escolaridade, quatro das nove profissionais entrevistadas afirmaram desconhecer as práticas daquele profissional. Enquanto isso, as demais integrantes da equipe não conseguiram explicar, de forma abrangente, a atuação do terapeuta ocupacional, pontuando apenas algumas práticas, conforme relato a seguir:

[...] um paciente assim, que fica em casa sem ter o que fazer [...] chegando um profissional, conversando com ele, desenvolvendo, dando algumas habilidades... Isso já ajuda bastante a preencher o psicológico dessa pessoa, evitando danos [...] (Profissional 4 - ESF).

É... ele seria pra... tipo reabilitar. Sei lá. Fazer a pessoa voltar a trabalhar (Profissional 7 - ESF).

[...] é... aquele [profissional] das bolinhas. Eu só lembro dessa das bolinhas, fazer alguma coisa pra despertar, que ela [usuária] não fica assim, só no ócio (Profissional 11- ESF).

Nesse sentido, Gozzi e Soares (2011) afirmam que a entrada do terapeuta ocupacional na APS é resultado do significativo investimento do SUS neste nível de atenção. Os integrantes da equipe de saúde são capazes de identificar algum impedimento para o desenvolvimento das atividades cotidianas dos usuários e associá-los à atuação do terapeuta ocupacional, mesmo que haja dificuldade em compreender o papel deste profissional.

Para as profissionais com nível superior de escolaridade, a atuação do terapeuta ocupacional na reabilitação física e psicossocial é observada com maior destaque. Ressaltaram também açóes de educação permanente, matriciamento, visitas domiciliares, abordagens grupais e atendimento individualizado, utilizaçáo de recursos de tecnologia assistiva, busca ativa de usuários, parcerias na comunidade, atividades intersetoriais relativas à saúde e práticas que envolvem todas as faixas etárias.

A gente solicita uma visita do terapeuta ocupacional a uma criança que não tá conseguindo desenvolver uma certa atividade. Eu já vi uma prática que a menina [terapeuta ocupacional] fez uma colher com um cabo adaptado, né, pra um paciente que não tinha mais uma parte da mão. [...] eu nem sabia que ela trabalhava daquela forma. Ela produziu uma colher só pra aquele paciente (Profissional 2 - ESF).

[...] [a Terapia Ocupacional] vem por trás da questão física em si, a questäo... emocional... O que a mobilidade do paciente reflete em outros aspectos [...] outra coisa do terapeuta ocupacional, nesse sentido, ele é muito parceiro e é uma coisa mais visivel, mais palpável de melhora do sujeito. Assim, d'ele [usuário] poder, na sua capacidade, realizar o que é possivel da melhor maneira que normalmente, sem o terapeuta ocupacional, ele não saberia desenvolver (Profissional 2 - NASF).

[...] tá muito ligada com a prática do fisioterapeuta e do psicólogo. Eu acho que tem um foco muito grande, pelo menos na nossa realidade, na área de saúde mental. E muito forte no Programa de Saúde na Escola. Além assim, de casos sequelados de AVC, principalmente, e de Hansen (Profissional 1 - NASF).

Tais afirmaçốes demonstram que foram observados os aspectos centrais do fazer do terapeuta ocupacional e da relação de suas açóes com as necessidades da APS, as quais, de acordo com Araújo et al. (2013), dizem respeito às questóes sociais, psíquicas e de reabilitação física, no âmbito de promoção e recuperação da saúde.

Paiva et al. (2013) entendem como atribuições da Terapia Ocupacional: açôes de promoção, prevenção e reabilitação da saúde; cura; práticas integrativas; humanizaçáo dos serviços e educação permanente. Portanto, a atuaçáo do terapeuta ocupacional, que utiliza as atividades significativas como recurso, torna possível alcançar a transformação de comportamentos e melhorar a qualidade de vida dos indivíduos assistidos na ESF.

Para alguns autores, as práticas dos terapeutas ocupacionais no NASF estão relacionadas à atenção integral à saúde, apresentando maior enfoque na realização de açóes preventivas, de promoção e de educação em saúde; nas açôes de reabilitação e de saúde mental e na atuação do desempenho funcional - como as Atividades da Vida Diária e Atividades Instrumentais da Vida Diária, bem como a integração social (LIMA; FALCÁO, 2014; SILVA; MENTA, 2014).

No entanto, Araújo et al. (2013) consideram a maioria das experiências do terapeuta ocupacional no NASF ainda muito direcionadas para a assistência e limitadas do ponto de vista do matriciamento, como preconizado nas diretrizes do NASF, havendo necessidade de revisão destas práticas. 
Dessa maneira, foi possível observar certa dificuldade na compreensão das especificidades do terapeuta ocupacional na APS, por parte dos profissionais entrevistados, quando solicitada a descrição de práticas realizadas pelo terapeuta ocupacional. Essa dificuldade foi mais evidente nas respostas das profissionais que possuem nível médio e técnico de escolaridade. Ou seja, apesar da relevância da atuação do terapeuta ocupacional na APS, sua prática ainda não é completamente compreendida por todos os integrantes da equipe.

Em relação às práticas compartilhadas com o terapeuta ocupacional, seis das nove profissionais com nível médio e técnico de escolaridade afirmaram ainda não ter realizado qualquer ação em conjunto com o terapeuta ocupacional. As demais profissionais citaram o compartilhamento das seguintes atividades: visita domiciliar, orientação dos pais pelo Programa Saúde na Escola, educação em saúde e discussão de casos.

Nesse sentido, a organização de trabalho dos NASF deve ser estruturada priorizando o atendimento interdisciplinar e compartilhado, com troca de saberes, capacitação e responsabilidades mútuas, proporcionando experiência para todos os profissionais da equipe (BRASIL, 2014). Quanto às profissionais com nível superior de escolaridade da ESF, com exceção de uma delas, todas afirmaram ter compartilhado com o terapeuta ocupacional as seguintes práticas: educação em saúde, atuação no Programa Saúde na Escola, visita domiciliar, consulta compartilhada e grupos de intervenção. As profissionais do NASF também citaram a promoção em saúde mental, grupos para desenvolvimento da linguagem, grupos de atendimento aos idosos $\mathrm{e}$ às gestantes, visitas e orientação aos pacientes acamados, aos pacientes com acidente vascular encefálico e intervençóes relacionadas às alterações no desenvolvimento da criança.

Em educação continuada, em palestras já, atendimento compartilhado ainda não tive a oportunidade, é... na questão do PSE, bastante, bastante presente. E visita domiciliar, já tive a oportunidade de participar com o terapeuta do NASF (Profissional 1 - ESF).

Já fiz várias visitas juntas e grupos de gestantes com a participação de T.O. e psicólogo. Eu acho que, dentre todas as profissóes do NASF, é a que mais se compartilha, eu acho, é o terapeuta ocupacional e o psicólogo. A gente fez grupo, faz visitas; algumas vezes, escutas qualificadas junto com o terapeuta ocupacional os ganhos são muito (Profissional 2 - NASF).
De acordo com Silva e Menta (2014), o trabalho no NASF estimula a realização de práticas coletivas e preventivas por parte dos terapeutas ocupacionais. Para isso, se faz necessária a interação das equipes NASF e Saúde da Família, que pode ser efetivada por meio de discussóes constantes. Tal estratégia favorece a análise do profissional de T.O. quanto à situação de saúde da população e à busca da resolução dos problemas identificados, reafirmando as recentes propostas da Terapia Ocupacional.

O compartilhamento de práticas faz parte das intervençóes mais realizadas pelos profissionais dos NASF. Além de fortalecer o vínculo do usuário com a EqSF e o NASF, facilita a comunicação e a coleta de dados, assim como permite a pactuação de açóes por meio do profissional da EqSF (BRASIL, 2014).

Dessa maneira, o compartilhamento de práticas de outros profissionais com o terapeuta ocupacional oportuniza a maior compreensão de sua atuação, o que pode promover troca de saberes e trazer maiores benefícios à população atendida.

\subsection{A compreensão das equipes de saúde sobre o potencial de atuação do terapeuta ocupacional e sua importância no NASF}

No que concerne à identificação das possíveis práticas do terapeuta ocupacional, os profissionais com nível médio e técnico de escolaridade apresentaram dificuldade para descrevê-las. Cinco das nove entrevistadas afirmaram desconhecer possíveis atividades, enquanto as demais deram sugestóes pouco consistentes - ou que se distanciam - das atribuiçóes daquele profissional e das diretrizes do NASF, como evidenciado na fala a seguir:

Não sei se medicação pode. Mas acho que orientação; fisioterapia também. Eu acho que basicamente é isso (Profissional 5 - ESF).

As profissionais da EqSF com nível superior de escolaridade trouxeram, como sugestóes, práticas que já são realizadas pelo terapeuta ocupacional, entre elas: atividade educativa, visita domiciliar, atendimento na unidade, matriciamento, prevençáo de incapacidades, orientaçáo aos pacientes e seus familiares.

Bom, aqui, eu acho que desempenham já muito bem, né? Mas o que eu gosto e que eles fazem é justamente a parte da educação continuada [...] (Profissional 1 - ESF). 
As profissionais do NASF sugeriram a formação de grupos para a exploração de práticas artesanais, adaptaçôes de utensílios, educação em saúde, orientação quanto ao uso de órteses após internação, parceria com o fonoaudiólogo no desenvolvimento da linguagem, estimulação do desenvolvimento global da criança, criação de grupos que contemplem todas as faixas etárias e realização de articulaçôes intersetoriais para favorecer o acesso da população à saúde.

Assim, eu acho que grupos; grupos, claro que já tem alguns, mas que podia ter outros. Talvez em, em... não sei. É... explorando mais práticas artesanais, alguma coisa desse tipo (Profissional 1-NASF).

E eu acho que o terapeuta ocupacional também é muito importante nesse sentido de ver esse sujeito como um sujeito especial, mas um sujeito capaz, dentro das limitaçôes, que não são limitaçōes físicas no sentido da locomoção, mas física de capacidade de saúde mental mesmo. De poder realizar determinadas coisas com suas... com suas limitaçôes em outro sentido que não só o físico e o movimento (Profissional 2 - NASF).

Nesse contexto, destacamos a importância do apoio matricial como ferramenta que favorece a organização e o aprimoramento do trabalho na APS, fortalece a capacidade de atenção à saúde, valoriza a interdisciplinaridade e torna possível a regulação das redes assistenciais; além disso, oferece aos profissionais e à equipe um apoio especializado, que atua de forma interativa, com suporte técnico-pedagógico e retaguarda assistencial. Dessa forma, podem ser realizadas atividades como o atendimento compartilhado, acolhimento, construção de projeto terapêutico singular, assim como avaliação de estratégias para atender à demanda reprimida. Vale ressaltar que tais açôes se dão de forma articulada com as USF, unidade de referência e demais setores (BRASIL, 2014; LIMA; FALCÃO, 2014; CUNHA; CAMPOS, 2011).

Em relação à importância da atuação do terapeuta ocupacional no NASF, apenas três das nove profissionais com nível médio e técnico de escolaridade da ESF citaram: a visão de um profissional com atuação diferente daquela ofertada pela ESF; a possibilidade de oferecer assistência à população; e as orientaçóes dadas à população e aos profissionais.

Duas das três profissionais da ESF com nível superior de escolaridade identificaram a educação permanente e a continuidade do cuidado ofertada na USF como potencialidades para as práticas da Terapia Ocupacional no NASF. Três das cinco profissionais do NASF citaram: o olhar diferente, a visão integral do profissional, o apoio e a articulação com a família.

\section{[...] essa articulação com a família é muito} importante, eu acho que o terapeuta ocupacional tem uma função fundamental nessa questão da família, da ajuda, da compreensão. De poder, na dificuldade financeira, de moradia, de você, nesse espaço de dificuldade, ajudar várias coisas na rotina do paciente, melhorem suas condiçöes de vida. Acho que esse é o objetivo (Profissional 2 - NASF).

Para Marins e Emmel (2011), o terapeuta ocupacional é habilitado para ofertar à população elementos que possibilitem a autonomia e funcionalidade nos contextos da saúde - física, mental e/ou social. Para as autoras, a formaçáo do terapeuta ocupacional propicia a articulação em equipes multiprofissionais, nas quais este profissional apresenta forte contribuição.

O campo da APS se faz duplamente complexo, uma vez que desafia os profissionais da área da saúde a reestruturarem seu modelo de formação - adequando o perfil profissional às necessidades da APS -, bem como exige evidente definição das competências específicas de cada profissão, de forma que os limites das áreas sejam respeitados, mantendo a oferta de ações advindas dos saberes específicos de cada profissão (ROCHA; PAIVA; OLIVEIRA, 2012). Assim, dentro da equipe, os profissionais devem construir uma identidade grupal, ao mesmo tempo que mantêm a identidade profissional adquirida durante sua formação acadêmica (PEIXOTO, 2010).

Dessa forma, cabe ao terapeuta ocupacional, apresentar aos demais profissionais da equipe de saúde as especificidades de sua profissão. Na APS, isso pode ocorrer por meio do apoio matricial, dos espaços de educação permanente, de educação popular em saúde, do compartilhamento de práticas, da discussão de casos, da construção do Programa Terapêutico Singular e demais açôes, além da produção científica.

Quando questionadas sobre as práticas que gostariam de compartilhar com o terapeuta ocupacional, quatro, das nove profissionais com nível médio e técnico de escolaridade, responderam: discussão de casos, educação em saúde mediante palestras, saúde da criança e grupo voltado para pessoas com depressão. As demais profissionais náo souberam responder.

A maioria das profissionais da EqSF com nível superior citou como práticas que poderiam realizar com o terapeuta ocupacional: a consulta compartilhada, principalmente na puericultura, visita domiciliar e grupos de intervenção em saúde. A equipe do NASF relatou, além das atividades citadas pela EqSF, o 
matriciamento, as açóes no Programa Saúde na Escola, intervençóes voltadas para as gestantes e grupo de saúde do idoso.

É completamente diferente se eu fizer uma visita só e se eu fizer a visita junto de um terapeuta ocupacional. Porque a gente tem a tendência de ver coisas da nossa área, nosso núcleo de saber. Dai [...] mesmo que ele [terapeuta ocupacional] não esteja presente, se ele já matriciou da outra vez, você já esteve com ele, você já percebeu certas coisas, você já questiona coisas que antigamente você não questionava por conta de sua capacitação ser distinta. Então assim, eu acho que é uma situação muito rica, em todos os sentidos, em todas as atividades realizadas pelo NASF é... Esse compartilhamento é essencial (Profissional 2 NASF).

Para Shcerer, Pires e Jean (2013), o trabalho no modelo Saúde da Família é complexo, é um desafio para os profissionais que guiam sua atuação pelo princípio da integralidade e pelo compartilhamento de práticas e saberes, baseados na multi e interdisciplinaridade. Para que esta última ocorra, é necessária a superação de desafios impostos pelas delimitaçóes disciplinares. O modelo de gestão e as condiçóes materiais e organizacionais são condicionantes para a qualidade do trabalho dos profissionais. Ou seja, é fundamental o esforço por parte dos profissionais diante da complexidade e das demandas da APS, para ofertar serviços de qualidade - a interdisciplinaridade contribui ricamente para o reconhecimento das práticas de seus profissionais e interação entre eles.

\subsection{Desafios para as práticas da Terapia Ocupacional no NASF}

A maioria das profissionais com nível médio e técnico de escolaridade afirmou desconhecer os desafios para as práticas da Terapia Ocupacional no NASF. As demais acreditam que a falta de conhecimento e consequente desvalorização da Terapia Ocupacional, além da dificuldade da continuidade do serviço diante dos entraves da rede de saúde, podem ser considerados desafios.

[...] ao meu ver é um trabalho que precisa ser ampliado, ter mais assim, reconhecimento, ser valorizado mais ainda, ter um campo amplo de... de, assim, de conhecimento pras pessoas, pra poder valorizar mais o profissional que elas são (Profissional 1 - ESF).

A grande demanda para açôes de saúde mental, o processo de trabalho na equipe no que diz respeito às relaçóes entre trabalhadores, o desconhecimento das práticas da Terapia Ocupacional e a falta de estrutura e materiais adequados para sua realizaçáo foram citados pelos profissionais, com nível superior de escolaridade, da EqSF.

\section{$O$ desafio até das pessoas entenderem o trabalho do terapeuta ocupacional. A comunidade, os profissionais, todos (Profissional 3 - ESF).}

A equipe NASF aponta a falta de conhecimento como um dos principais desafios. Além deste, foi citada a falta de recursos.
Eu acho que tem vários, principalmente a questão de recursos, né? Recursos de aparelhos, de coisas que vocês podem facilitar a vida do sujeito, mas que de alguma forma o sistema público não disponibiliza [...] Por exemplo, uma pessoa que tem hanseniase, que tem algumas dificuldades, algumas limitações físicas de escovar dentes. Tem tantas adaptaçóes que poderiam ser feitas e que no final das contas a gente... Vocês, no caso, náo conseguem realizar pela falta de recursos materiais (Profissional 2 - NASF).

\section{[...] Eu acho que se a unidade for mais esclarecida, se as agentes de saúde fossem mais esclarecidas, eu acho que o terapeuta ocupacional ele tinha mais abertura, né, dentro dessas unidades (Profissional 3 - NASF).}

Em relação ao reconhecimento do papel do terapeuta ocupacional, a legislação básica em saúde pública e as normas operacionais são conhecidas entre gestores e profissionais. Entretanto, são consideradas escassas as normatizações sobre procedimentos ou metodologias de intervenção da Terapia Ocupacional na APS (BEIRÃO; ALVES, 2010). Para alguns autores, a experiência de trabalho no SUS pode não ser suficiente para que se conheça a regulamentação e portarias que embasam a atuação neste nível de atenção, e, mesmo compartilhando práticas, os profissionais podem não ter conhecimento da atuação de outros membros da equipe, o que justifica a busca da qualificação profissional para o trabalho e a utilização de novas tecnologias (LIMA; FALCÃO, 2014; BEIRÃO; ALVES, 2010).

De acordo com Donnelly et al. (2013), a comunicação entre os componentes da equipe de saúde, a confiança e a compreensão dos papéis profissionais são fatores essenciais para a integração da Terapia Ocupacional na APS. Em uma pesquisa realizada com terapeutas ocupacionais do NASF de Fortaleza (CE), estes profissionais relataram que a inserção na APS foi desafiadora, devido à falta de compreensão do seu papel, tanto por parte da EqSF quanto por parte dos próprios terapeutas ocupacionais. Diante disso, foram 
lançadas estratégias que vão desde a apresentação da equipe até as oficinas de qualificação do NASF. Outros desafios também foram apontados: as condiçóes de trabalho, o estabelecimento de vínculo na produçáo do trabalho em saúde, a precarização do trabalho e a escassez de materiais (REIS; VIEIRA, 2013).

Apesar da evoluçáo da Terapia Ocupacional na APS, Rocha, Paiva e Oliveira (2012) ressaltam a necessidade de avanços quantitativos e qualitativos em relação às suas açôes, atribuiçóes e tecnologias. Para isso, se faz necessário o aprofundamento de estudos e de debates sobre o tema, no sentido de alcançar seu fortalecimento e sua instrumentalização.

\section{Conclusão}

Identificamos restriçôes quanto à compreensão dos profissionais da APS, principalmente daqueles com nível médio e técnico de escolaridade, no que diz respeito à intervençâo do terapeuta ocupacional. As dificuldades para reconhecer as práticas próprias do terapeuta ocupacional foram evidenciadas mesmo quando há compartilhamento de trabalho entre este profissional e os demais integrantes da equipe. Algumas hipóteses podem explicar tal fenômeno, entre elas: falha no compartilhamento dessas práticas, pouco contato entre os profissionais ou carência de discussóes das atividades. Essas falhas podem ser corrigidas (ou ocorrer) pela forma como se tem conduzido o matriciamento. Tais hipóteses merecem maior averiguação. Alguns dos profissionais entrevistados fizeram observaçóes significativas quanto à atuação do terapeuta ocupacional, entre elas: os resultados obtidos mediante sua intervenção, sua visão holística e integral, sua contribuição para a equipe de saúde, e a importância do compartilhamento de práticas com o terapeuta ocupacional.

No entanto, ressaltamos a necessidade de implementar estratégias de superaçáo das lacunas, no conhecimento da equipe, quanto às especificidades da Terapia Ocupacional. É preciso explorar soluçôes como o compartilhamento de práticas, na discussão destas, junto às equipes de saúde, enquanto processo de matriciamento e educação permanente em saúde. Ressaltamos que a compreensão do papel do terapeuta ocupacional favorece a sua inserção na APS de forma mais efetiva e possibilita ampliar a oferta de cuidado aos usuários.

\section{Referências}

AMERICAN OCCUPATIONAL THERAPY ASSOCIATION - AOTA. Estrutura da prática da Terapia Ocupacional: domínio e processo. Revista de Terapia
Ocupacional da Universidade de São Paulo, São Paulo, v. 26, p. 1-49, 2015. Edição Especial. http://dx.doi. org/10.11606/issn.2238-6149.v26iespp1-4.

ARAÚJO, K. R. A. et al. Experiências da terapia ocupacional em um Núcleo de Apoio à Saúde da Família (NASF) do Distrito Federal. Gestão e Saúde, Brasília, v. 4, n. 3, p. 963-971, 2013. Disponível em: <http://www. gestaoesaude.unb.br/index.php/gestaoesaude/article/ view/539>. Acesso em: 02 dez. 2013.

BAISSI, G.; MAXTA, B. S. B. Experiência da Terapia Ocupacional no cuidado familiar em um serviço de Atenção Primária em Saúde. Cadernos de Terapia Ocupacional da UFSCar, São Carlos, v. 21, n. 2, p. 413-422, 2013. Disponível em: <http://www.cadernosdeterapiaocupacional.ufscar.br/index.php/cadernos/article/ view/828/453>. Acesso em: 9 jan. 2016.

BARDIN, L. Análise de conteúdo. Lisboa: Ediçōes, 1977.

BASSI, B. G. C.; MALFITANO, A. P. S.; BIANCHI, P. C. O terapeuta ocupacional na Atenção Básica em Saúde: a representatividade em revistas e nos congressos brasileiros da área. Cadernos de Terapia Ocupacional da UFSCar, São Carlos, v. 20, n. 3, p. 443-454, 2012.

BEIRÃO, R. O. S.; ALVES, C. K. A. Terapia Ocupacional no SUS: refletindo sobre a normatização vigente. Cadernos de Terapia Ocupacional da UFSCar, São Carlos, v. 18, n. 3, p. 231-246, 2010. Disponível em: $<$ http://www.google.com.br/url?sa=t\&rct=j\&q=\&es $\mathrm{rc}=\mathrm{s} \&$ source $=$ web $\& c d=9 \& v e d=0 \mathrm{CGcQFjAI} \& \mathrm{url}=\mathrm{h}$ ttp\%3A\%2F\%2Fwww.cadernosdeterapiaocupacional.ufscar.br\%2Findex.php $\% 2$ Fcadernos $\% 2$ Farticle \%2Fdownload\%2F378\%2F293\&ei=_DLZUuuHJo fLkAfLo4G4CQ\&usg=AFQjCNFTGNSqd1-XXaL-snitlDe_2Lk0A\&bvm=bv.59568121,d.eW0>. Acesso em: 06 dez 2014.

BRASIL. Ministério da Saúde. Portaria no 692/GM de 25 de março de 1994. Diário Oficial [da] República Federativa do Brasil, Brasília, DF, 29 mar. 1994. Disponível em: <http://sna.saude.gov.br/legisla/legisla/prog_pacs_ psf/>. Acesso em: 13 nov. 2013.

BRASIL. Conselho Nacional de Secretários de Saúde. SUS: avanços e desafios. Brasília: CONASS, 2006.

BRASIL. Ministério da Saúde. Portaria no 154/GM, de 24 de janeiro de 2008. Diário Oficial [da] República Federativa do Brasil, Brasília, DF, 24 jan. 2008. Disponível em: <http://189.28.128.100/dab/docs/legislacao/portaria154_24_01_08.pdf>. Acesso em: 21 nov. 2013.

BRASIL. Ministério da Saúde. Diretrizes do NASF: Núcleo de Apoio à Saúde da Família. Brasília: Ministério da Saúde, 2010. Cadernos de Atençâo Básica, n. 27. Disponível em: <http://189.28.128.100/dab/docs/publicacoes/cadernos_ab/abcad27.pdf $>$. Acesso em: 20 nov. 2013.

BRASIL. Conselho Nacional de Saúde. Resoluçấo $n^{\circ}$ 466, de 12 de dezembro de 2012. Diretrizes e normas 
regulamentadores de pesquisas envolvendo seres humanos. Diário Oficial [da] República Federativa do Brasil, Brasília, DF, 12 dez. 2012a. Disponível em: <http:// conselho.saude.gov.br/resolucoes/2012/Reso466.pdf>. Acesso em: 15 nov. 2013.

BRASIL. Ministério da Saúde. Política Nacional de Atenção Básica. Brasília: Ministério da Saúde, 2012b. Disponível em: <http://189.28.128.100/dab/docs/publicacoes/geral/pnab.pdf>. Acesso em: 14 dez. 2015.

BRASIL. Ministério da Saúde. Núcleo de apoio â Saúde da Família - Volume 1: ferramentas para a gestão e para o trabalho cotidiano. Brasília: Ministério da Saúde, 2014. Cadernos de Atenção Básica, n. 39. Disponível em: <http://bvsms.saude.gov.br/bvs/publicacoes/nucleo_apoio_saude_familia_cab39.pdf.>. Acesso em: 3 jan. 2016.

CAMPOS, G. W. S.; DOMITTI, A. C. Apoio matricial e equipe de referência: uma metodologia para gestão do trabalho interdisciplinar em saúde. Cadernos de Saúde Pública, Rio de Janeiro, v. 23, n. 2, p. 399-407, 2007. Disponível em: <http://www.scielo.br/scielo. php?script=sci_arttext $\&$ pid $=$ S0102-31 X X20070002000 $16 \& \operatorname{lng}=$ en \&nrm=iso $>$. Acesso em: 5 mar. 2014.

CUNHA, G. T.; CAMPOS, G. W. S. Apoio Matricial e Atenção Primária em Saúde. Saúde e Sociedade, São Paulo, v. 20, n. 4, p. 961-970, 2011. Disponível em: <http://www.scielo.br/pdf/sausoc/v20n4/13.pdf>. Acesso em: 6 set. 2014

DONNELLY, C. et al. The integration of occupational therapy into primary care: a multiple case study design. BMC Family Practice, London, v. 14, n. 60, p. 1-12, 2013. Disponível em: <http://www.ncbi.nlm.nih.gov/ pmc/articles/PMC3663696/>. Acesso em: 20 nov. 2013.

ELlERY, A. E. L.; PONTES, R. J. S.; LOIOLA, F. A. Campo comum de atuação dos profissionais da Estratégia Saúde da Família no Brasil: um cenário em construção. Physis: Revista de Saúde Coletiva, Rio de Janeiro, v. 23, n. 2, p. 415-437, 2013. Disponível em: <http://www. scielo.br/scielo.php?script $=$ sci_arttext \&pid $=$ S0103-73312013000200006\&lng=en\&nrm=iso > . Acesso em: 19 dez. 2015.

GOZZI, A. P. N. F.; SOARES, L. B. T. Solicitando o olhar do Terapeuta Ocupacional: o exercício do apoio matricial em uma Unidade de Saúde da Família de São Carlos - SP. Cadernos de Terapia Ocupacional da UFSCar, São Carlos, v. 19, p. 1-9, 2011. Suplemento Especial. Disponível em: <http://tocoletiva.com.br/wp-content/uploads/2012/04/ Alana-TC0617-3.pdf >. Acesso em: 21 jan. 2106.

JACOBS, K. Dicionário de Terapia Ocupacional: guia de referência. São Paulo: Editora Roca, 2006.

LIMA, A. C. S.; FALCÃO, I. V. A formação do terapeuta ocupacional e seu papel no Núcleo de Apoio à Saúde da Família - NASF do Recife, PE. Cadernos de
Terapia Ocupacional da UFSCar, São Carlos, v. 22, n. 1, p. 3-14, 2014. Disponível em: <http://www.cadernosdeterapiaocupacional.ufscar.br/index.php/cadernos/ article/view/970 >. Acesso em: 21 jan. 2016.

LOMBARDO, I. L.; AYUSO, D. M. R. Terapia ocupacional en La cartera de servicios de atención primaria: ¿ esposible? Revista Terapia Ocupacional Galicia (ACoruña), Espanha, v. 9, n. 16. p. 1-30, 2012. Disponível em: <http://www.revistatog.com/num16/pdfs/original8. pdf $>$. Acesso em: $05 \mathrm{dez} .2013$

MARINS, S. C. F.; EMMEL, M. L. G. Formação do terapeuta ocupacional: acessibilidade e tecnologias. $\mathrm{Ca}$ dernos de Terapia Ocupacional da UFSCar, São Carlos, v. 19, n. 1, p. 37-52, 2011. Disponível em: <http://www. cadernosdeterapiaocupacional.ufscar.br/index.php/cadernos/article/view/420/311>. Acesso em: 15 jan. 2016.

MENDES, E. V. As redes de atenção à saúde. Brasília: Organização Pan-Americana da Saúde, 2011. Disponível em: <http://www.conass.org.br/pdf/Redes_de_Atencao. pdf $>$. Acesso em: 11 jan. 2016

PAIVA, L. F. A. et al. A Terapia Ocupacional na residência multiprofissional em Saúde da Família e Comunidade. Cadernos de Terapia Ocupacional da UFSCar, São Carlos, v. 21, n. 3, p. 595-600, 2013. Disponível em: <http://www.cadernosdeterapiaocupacional.ufscar.br/ index.php/cadernos/article/view/919/471>. Acesso em: 20 jan. 2015.

PEIXOTO, L. S. A. A dinâmica da identidade profissional em equipes multiprofissionais. 2010. 255 f. Dissertação (Mestrado em Psicologia) - Universidade Federal da Bahia, Salvador, 2010

REIS, F; VIEIRA, A. C. V. C. Perspectivas dos terapeutas ocupacionais sobre sua inserção nos Núcleos de Apoio à Saúde da Família (NASF) de Fortaleza, CE. Cadernos de Terapia Ocupacional da UFSCar, São Carlos, v. 21, n. 2, p. 351-360, 2013

ROCHA, E. F.; PAIVA, L. F. A.; OLIVEIRA, R. H. Terapia ocupacional na Atenção Primária à Saúde: atribuiçóes, açóes e tecnologias. Cadernos de Terapia Ocupacional da UFSCar, São Carlos, v. 20, n. 3, p. 351-361, 2012. Disponível em: <http://www.cadernosdeterapiaocupacional.ufscar.br/index.php/cadernos/article/view/679/39>. Acesso em: 6 fev. 2015

SCHERER, M. D. A.; PIRES, D. E. P.; JEAN, R. A construção da interdisciplinaridade no trabalho da Equipe de Saúde da Família. Ciência \& Saúde Coletiva, Rio de Janeiro, v. 18, n. 11, p. 3203-3212, 2013. Disponível em: <http://www.scielosp.org/scielo.php?script=sci_ arttext\&pid=S1413-81232013001900011\&lng=en\&nr $\mathrm{m}=$ iso $>$. Acesso em: 08 jan. 2015.

SILVA, A. T. C. et al. Núcleos de Apoio à Saúde da Família: desafios e potencialidades na visão dos profissionais da Atenção Primária do Município de São Paulo, 
Brasil. Cad. Saúde Pública, Rio de Janeiro, v. 28, n. 11, p. 2076-2084, 2012. Disponível em: <http://www.scielo.br/scielo.php?script=sci_arttext\&pid=S0102-311X20 $12001100007 \& \operatorname{lng}=p t \& n r m=i s o>$. Acesso em: 16 jan. 2015.

SILVA, R. A. S.; MENTA, S. A. Abordagem de terapeutas ocupacionais em Núcleos de Apoio à Saúde da Família (NASF) no estado de Alagoas. Cadernos de Terapia Ocupacional da UFSCar, São Carlos, v. 22, n. 2, p. 243250, 2014. Disponível em: <http://www.cadernosdeto. ufscar.br/index.php/cadernos/article/view/604/532>. Acesso em: 15 nov. 2014.

SILVA, L. A.; CASOTTI, C. A.; CHAVES, S. C. L. A produção científica brasileira sobre a Estratégia Saúde da Família e a mudança no modelo de atenção. Cadernos de Saúde Pública, Rio de Janeiro, v. 18, n. 1, p. 221-232, 2013. Disponível em: <http://www. scielosp.org/scielo.php?script=sci_arttext\&pid=S1413$-81232013000100023 \& \operatorname{lng}=\mathrm{en} \& \mathrm{nrm}=\mathrm{iso}>$. Acesso em: 19 dez. 2015.

\section{Contribuição dos Autores}

Andréa Saraiva de Andrade é responsável pela concepção e realização da pesquisa, análise dos dados e redação do texto. Ilka Veras Falcão contribuiu com o planejamento da pesquisa, discussão dos dados e revisão do texto. Ambas autoras aprovaram a versão final do texto.

\section{Fonte de Financiamento}

Programa de Residência Multiprofissional em Saúde da Família da UFPE. 